E UROPEAN CENTRALAANK

WORKING PAPER SERIES

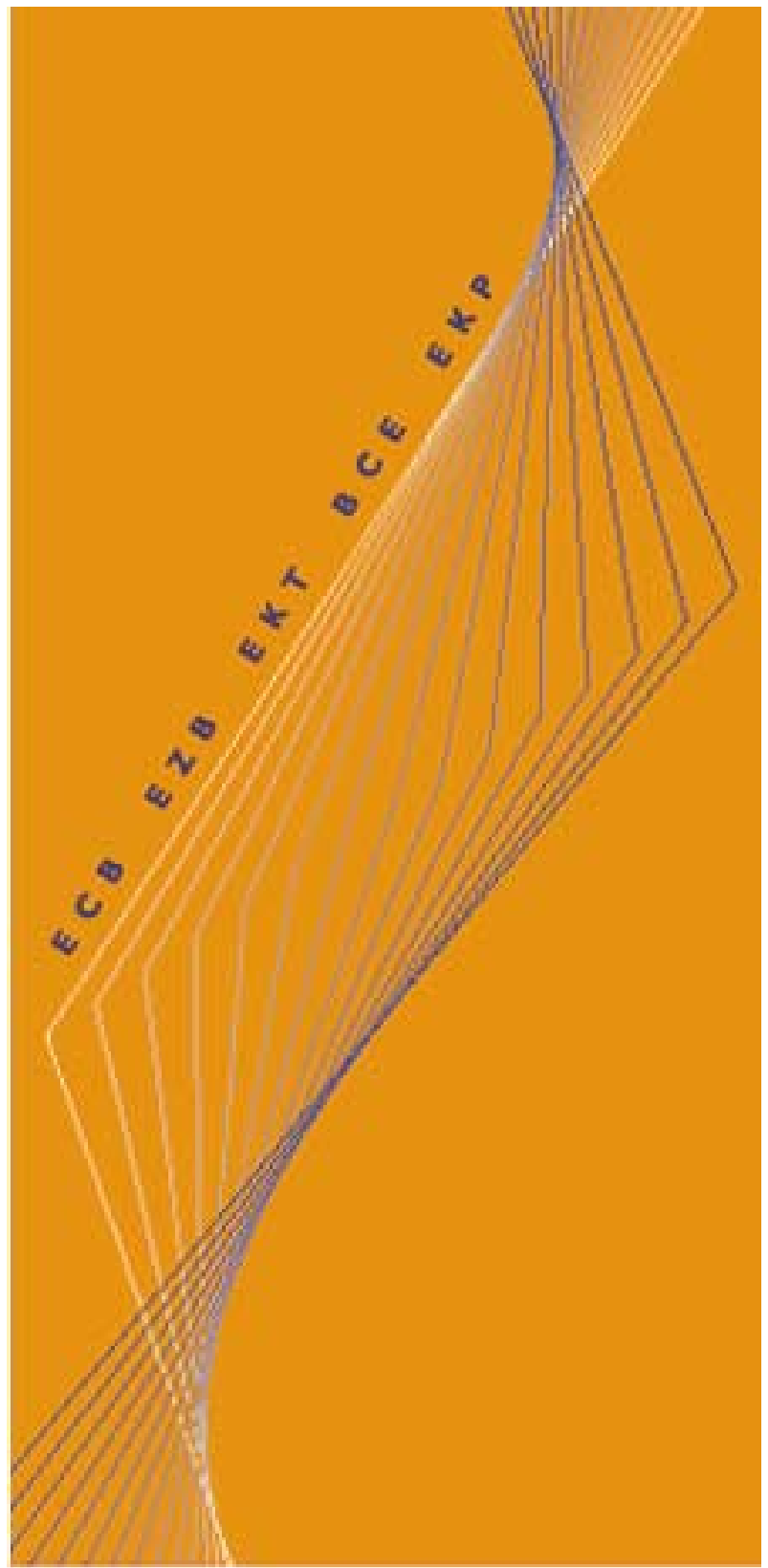

WORKING PAPER NO. 49

BUSINESS CYCLE AND MONETARY POLICY ANALYSIS IN A STRUCTURAL STICKYPRICE MODEL OF THE EURO AREA

BY MIGUEL CASARES

March 2001 

E U R P E A N C E N T A L B A N K

WORKING PAPER SERIES

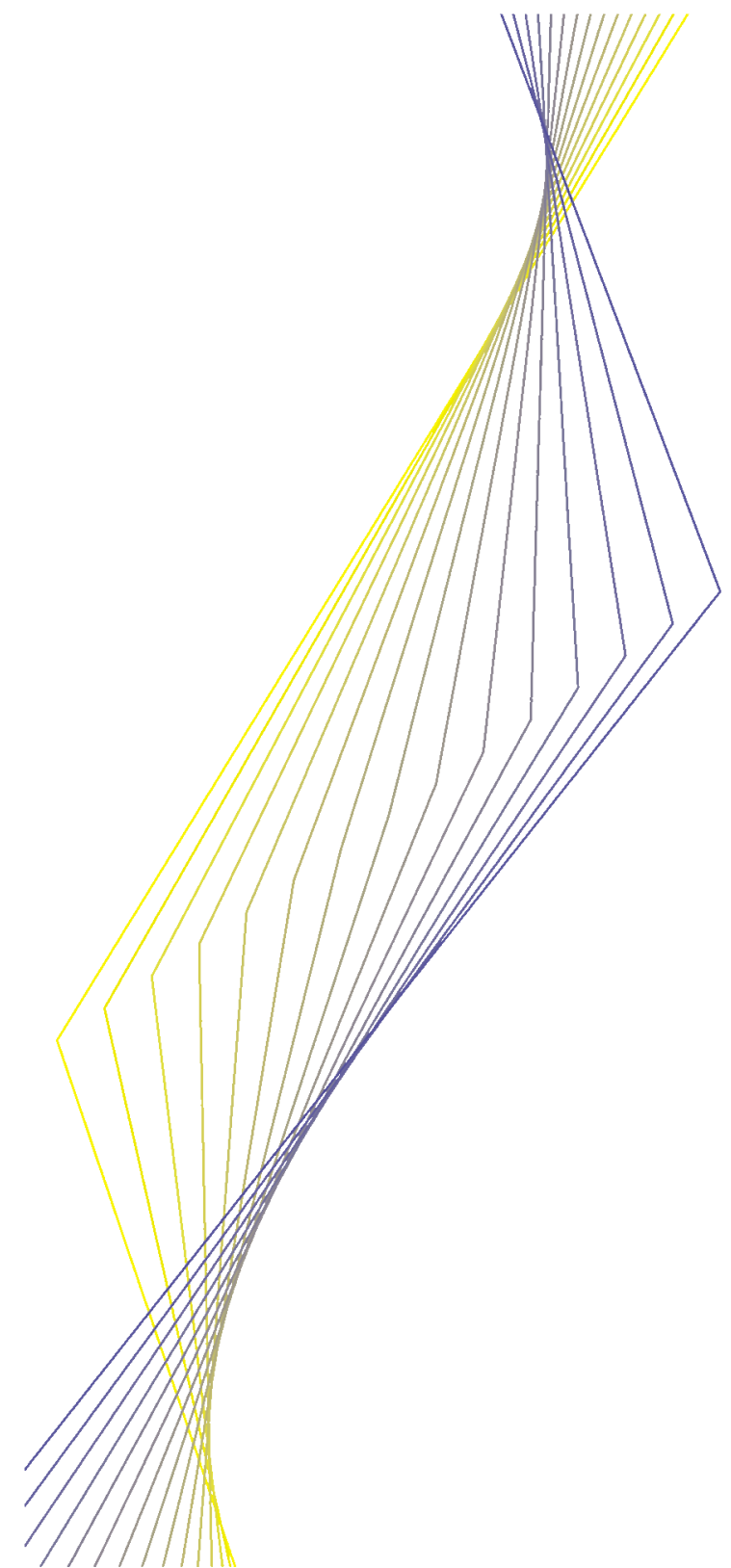

WORKING PAPER NO. 49

BUSINESS CYCLE AND

MONETARY POLICY ANALYSIS

IN A STRUCTURAL STICKY-

PRICE MODEL OF THE EURO

AREA

\author{
BY MIGUEL CASARES*
}

\title{
March 2001
}

* Miguel Casares, Departamento de Economía, Universidad Pública de Navarra, 31006, Pamplona, Spain, email: mcasares@unavarra.es. 
(C) European Central Bank, 200I

\begin{tabular}{|c|c|}
\hline \multirow[t]{3}{*}{ Address } & Kaiserstrasse 29 \\
\hline & D-603 I I Frankfurt am Main \\
\hline & Germany \\
\hline \multirow[t]{3}{*}{ Postal address } & Postfach 160319 \\
\hline & D-60066 Frankfurt am Main \\
\hline & Germany \\
\hline Telephone & +496913440 \\
\hline Internet & http://www.ecb.int \\
\hline Fax & +496913446000 \\
\hline Telex & 4 I I I44 ecb d \\
\hline
\end{tabular}

Reproduction for educational and non-commercial purposes is permitted provided that the source is acknowledged.

The views expressed in this paper are those of the authors and do not necessarily reflect those of the European Central Bank. 


\section{Contents}

\begin{tabular}{lrr}
\hline \multicolumn{2}{l}{ Abstract } & 5 \\
\hline 2 & Introduction & 7 \\
\hline $3 \quad$ The Model & 7 \\
\hline $4 \quad$ Bstimation and Calibration & 18 \\
\hline $6 \quad$ Conclusions & 22 \\
\hline References & 28 \\
\hline Figures & 30 \\
\hline European Central Bank Working Paper Series & 33 \\
\hline
\end{tabular}




\begin{abstract}
Structural models are a powerful tool for business cycle and monetary policy analysis because they are invariant to either policy changes or external shocks. In this paper, we derive a Sidrauski-type model in which both the demand and supply side are structural in the sense that the behavioral equations obtained are rigorously calculated from optimizing decisions of the individuals. Moreover, we introduce price stickiness on the supply side decisions so as to have relevant short-run real effects of monetary policy through the real interest rate channel. The resulting medium-size model will be calibrated and estimated for the euro area economies. As two examples of the applications of the model for the euro area, some simulations on business cycle and monetary policy analysis will be carried out.
\end{abstract}

Keywords: optimizing dynamic models, sticky prices, business cycle, Taylor rules.

JEL codes: E20, E32, E52. 


\section{Introduction}

This paper presents a structural medium-size model for business cycle and monetary policy analysis. The demand-side of the model is obtained from optimizing agents behavior in the context of the IS-LM framework recently used in the literature (Kerr and King (1996), McCallum and Nelson (1999), and Rotemberg and Woodford (1997)). Two extensions were incorporated here. First, the role of money as a medium of exchange is explicitly incorporated through a transaction costs function entering the household's budget constraint. Second, investment in capital goods is calculated endogenously from the first order conditions. Capital movements are smoothed due to adjustment costs of installing investment. Section 2 is devoted to describe the model. We take special attention on deriving the consumption, investment, money demand, and inflation structural equations.

Structural models with sticky prices are very appropriate for business cycle and monetary policy analysis because of its independence from the monetary/fiscal policy regime and its capability to explain short-run effects of these policies. Hence, the aggregate supply function will be obtained from the first order conditions of the model and the price index definition. In particular, price stickiness will arise from the assumption found in Calvo (1983) that sellers can change their price only under a fixed probability within a monopolistic competition scenario.

The resulting system of equations representing supply and demand behavior are policy invariant and therefore they can be estimated without being subject to the Lucas critique. The model will be estimated and calibrated for the euro area in Section 3 based on (if available) quarterly observations during the period 1970.1-1998.4.

In Section 4 of this work we check the business cycle patterns of the model by means of analyzing impulse response functions. The design of Taylor monetary policy rules in the euro area is another application of the model. Hence, the performance of Taylor rules under different coefficients will be compared in Section 5 aiming at providing some monetary policy recommendations. Conclusions will be listed in Section 6 .

\section{The Model}

The economy consists of a continuum of households that seek to maximize in period $t$ the expected sum of the current and discounted future utility values depending on the state of 
consumption preferences $\zeta$, and the level of consumption $c$

$$
E_{t} \sum_{j=0}^{\infty} \beta^{j} U\left(\zeta_{t+j}, c_{t+j}\right)
$$

where $\beta=\frac{1}{1+\rho}$ is the discount factor, $E_{t}[$.$] is the rational expectation operator conditional$ to all the information available in period $t$, and the standard utility function assumptions $U_{c}>0$, and $U_{c c}<0$ hold. Each household produces a different good and consumes a bundle of goods that purchases from the other households. Hence, $c_{t}$ denotes number of bundles of goods aggregated using constant-elasticity indexes as in Dixit and Stiglitz (1977).

Households use the available transactions technology to carry out purchases of other-thanproduced goods. In doing so, they need to spend some resources, namely, output resources according to the output-cost transactions approach at hand. ${ }^{1}$ Our transaction costs function represents the existing transactions technology. In particular, we assume that there is a functional form that gives the amount $h_{t}$ of output usages (or transaction costs) in period $t$ depending on the number of consumption bundles $c_{t}$, and the amount held of real money balances $m_{t}$ :

$$
h_{t}=h\left(c_{t}, m_{t}\right)
$$

with $m_{t}=\frac{M_{t}}{P_{t}^{A}}, M_{t}$ denoting nominal money and $P_{t}^{A}$ the aggregate price level. The signs of the first order and cross derivatives are $h_{c}>0, h_{m}<0$, and $h_{c m}<0$. The transactionsfacilitating property of money as a medium of exchange is represented through the signs $h_{m}<0$ and $h_{c m}<0$ which imply that the use of more monetary services reduces the total and marginal transactions costs.

Investment is set as the increment in the stock of capital net of depreciation decided for next period's production plan. Thus, we denote $x_{t}$ as the amount invested in period $t$ according to the relation

$$
x_{t}=k_{t+1}-(1-\delta) k_{t} .
$$

\footnotetext{
${ }^{1}$ Alternatively, we could think of transaction costs in terms of time resources and then the transaction cost function (shopping time function) would enter the time constraint instead of the budget constraint (see Casares (2000) for a formal representation of this model).
} 
Such amount $x_{t}$ is obtained by transforming part of output into capital goods. We assume that some adjustment costs arise during the installation of capital goods. ${ }^{2}$ Accordingly, there exists a function $C\left(x_{t}\right)$ that gives the adjustment costs in terms of output due to installing $x_{t}$ units of new capital goods.

The production function determines the amount of output $y_{t}$ produced in period $t$ by employing labor $n_{t}$, and the stock of capital $k_{t}$ provided an (exogenous) state of technology measured by $z_{t}$

$$
y_{t}=f\left(z_{t}, n_{t}, k_{t}\right) .
$$

It is assumed that $f($.$) is homogeneous of degree 1$ with the standard first and second order conditions $f_{n}>0, f_{k}>0, f_{n n}<0, f_{k k}<0$, and $f_{n k}>0$. Households produce in a monopolistic competition industry so as the quantity produced is sold in the final goods market according to the Dixit-Stiglitz single good demand function:

$$
f\left(z_{t}, n_{t}^{d}, k_{t}\right)=\left(\frac{P_{t}}{P_{t}^{A}}\right)^{-\theta} y_{t}^{A}, \quad \text { with } \theta>1
$$

where $P_{t}$ is the selling price, $P_{t}^{A}$ is again the aggregate price level, $y_{t}^{A}$ is the aggregate output, and $\theta$ is the constant elasticity to the relative price.

In real magnitudes, the budget constraint faced by the households is

$$
\begin{gathered}
g_{t}+\left(\frac{P_{t}}{P_{t}^{A}}\right)^{1-\theta} y_{t}^{A}-C\left(x_{t}\right)=c_{t}+x_{t}+h\left(c_{t}, m_{t}\right)+w_{t}\left(n_{t}-1\right)+ \\
m_{t}-\left(1+\pi_{t}\right)^{-1} m_{t-1}+\left(1+r_{t}\right)^{-1} b_{t+1}-b_{t},
\end{gathered}
$$

where $\pi_{t}$ is the rate of inflation $\left(\pi_{t}=\frac{P_{t}^{A}-P_{t-1}^{A}}{P_{t-1}^{A}}\right)$ and $r_{t}$ is the real interest rate. There are two sources of real income for the household: lump-sum real transfers from the government $\left(g_{t}\right)$, and their own demand-determined output production after subtracting the adjustments cost of investment. Income is spent on consumption $\left(c_{t}\right)$, on investment $\left(x_{t}\right)$, on paying the

\footnotetext{
${ }^{2}$ There can be various sources of adjustment costs: information costs, learning costs, start-up costs, etc. The key point is that investing in real assets is conceptually different from investing in financial assets (bonds).
} 
transaction costs $(h()$.$) , on payments to the labor force hired in the market \left(w_{t}\left(n_{t}-1\right)\right.$, with $w_{t}$ denoting the real wage and assuming a one-unit inelastic labor supply), and on increasing the amounts held of real money $\left(m_{t}-\left(1+\pi_{t}\right)^{-1} m_{t-1}\right)$ or bonds $\left(\left(1+r_{t}\right)^{-1} b_{t+1}-b_{t}\right)$.

As of period $t$, households make rational choices of $c_{t}, k_{t+1}, n_{t}, m_{t}, b_{t+1}$, and $P_{t}$ by maximizing (1) subject to the market demand condition (5), and the budget constraint (6). Regarding $P_{t}$ 's optimal decision, we assume as in Calvo (1983) that each seller can adjust the price with a probability associated equal to $1-\eta$ whereas they will have to stick to the last period price with a probability equal to $\eta$. Assuming the former state of nature, the resulting first order conditions include (5), (6), and ${ }^{3}$

$$
\begin{array}{cc}
U_{c_{t}}-\lambda_{t}\left(1+h_{c_{t}}\right)=0, & \left(c_{t}^{f o c}\right) \\
-\lambda_{t}\left(1+C_{x_{t}}\right)+\beta E_{t}\left[\lambda_{t+1}\left(1-\delta+(1-\delta) C_{x_{t+1}}\right)\right]+\beta E_{t}\left[\xi_{t+1} f_{k_{t+1}}\right]=0, & \left(k_{t+1}^{f o c}\right) \\
-\lambda_{t} w_{t}+\xi_{t} f_{n_{t}}=0, & \left(n_{t}^{f o c}\right) \\
-\lambda_{t}\left(1+h_{m_{t}}\right)+\beta\left[E_{t} \lambda_{t+1}\left(1+\pi_{t+1}\right)^{-1}\right]=0, & \left(m_{t}^{f o c}\right) \\
-\lambda_{t}\left(1+r_{t}\right)^{-1}+\beta E_{t} \lambda_{t+1}=0, & \left(b_{t+1}^{f o c}\right) \\
\sum_{j=0}^{\infty}\left((1-\theta) \beta^{j} \eta^{j} E_{t}\left[\lambda_{t+j}\left(\frac{P_{t}}{P_{t+j}^{t}}\right)^{-\theta} \frac{y_{t+j}^{A}}{P_{t+j}^{t}}\right]+\theta \beta^{j} \eta^{j} E_{t}\left[\xi_{t+j}\left(\frac{P_{t}}{P_{t+j}^{t}}\right)^{-\theta-1} \frac{y_{t+j}^{A}}{P_{t+j}^{A}}\right]\right)=0, & \left(P_{t}^{f o c}\right)
\end{array}
$$

where $\lambda_{t}$, and $\xi_{t}$ are respectively the Lagrange multipliers attached to the budget constraint and market demand constraint in period $t$.

\section{The consumption function.}

The consumption first order condition $\left(c_{t}^{f o c}\right)$ implies that the consumption shadow price (i.e., the Lagrange multiplier $\lambda_{t}$ ) is equal to the marginal utility of consumption divided by one plus the marginal transaction cost ${ }^{4}$

$$
\lambda_{t}=\frac{U_{c_{t}}}{1+h_{c_{t}}}
$$

Combining the previous expression with the bonds $\left(b_{t+1}^{f o c}\right)$ first order condition, it yields:

\footnotetext{
${ }^{3}$ For convenience, we use the notation $F_{x_{t}}=\frac{\partial F\left(x_{t}, y_{t}\right)}{\partial x_{t}}$ for the partial derivatives.

${ }^{4}$ Note that when there is no transaction cost we get to the standard consumption shadow price equation $\lambda_{t}=U_{c_{t}}$.
} 


$$
1+r_{t}=\beta E_{t}\left[\frac{U_{c_{t}}\left(1+h_{c_{t}}\right)^{-1}}{U_{c_{t+1}}\left(1+h_{c_{t+1}}\right)^{-1}}\right] .
$$

Let us assume that household's preferences are well represented by a constant relative risk aversion (CRRA) instantaneous utility function,

$$
\begin{aligned}
U\left(\zeta_{t}, c_{t}\right) & =\exp \left(\zeta_{t}\right) \frac{c_{t}^{1-\sigma}}{1-\sigma} \\
\text { with } \sigma & >0
\end{aligned}
$$

and the transaction technology is given by the following functional form:

$$
h\left(c_{t}, m_{t}\right)=\left\{\begin{array}{ll}
0 & \text { if } c_{t}=0 \\
b_{0}+b_{1} \frac{c_{t}^{b_{2}}}{m_{t}^{b_{3}}} \quad \text { if } c_{t}>0 & \\
\text { with } b_{0}, b_{1}, b_{2}, b_{3}>0, &
\end{array}\right\}
$$

Substituting both functional forms (8) and (9) in the first order condition (7) and then log-linearizing following the techniques described in Uhlig (1999), it yields the consumption function:

$$
\widehat{c}_{t}=E_{t} \widehat{c}_{t+1}-\vartheta^{c}\left(r_{t}-r^{s s}\right)+b_{3} h_{c}^{s s} \vartheta^{c}\left(\widehat{m}_{t}-E_{t} \widehat{m}_{t+1}\right)+\vartheta^{c}\left(\zeta_{t}-E_{t} \zeta_{t+1}\right)
$$

where $\vartheta^{c}=\frac{1}{\sigma+\left(b_{2}-1\right) h_{c}^{s s}(.)}$ is the semi-elasticity of consumption to changes in the real interest rate and "hat" variables represent percent deviations from steady state (e.g., $\left.\widehat{c}_{t}=\log \left(\frac{c_{t}}{c^{s s}}\right)\right) .^{5}$

\footnotetext{
${ }^{5}$ Alternatively, and assuming that the preferences shock is white noise, we can express the consumption function as follows

$$
\widehat{c}_{t}=\vartheta^{c} \zeta_{t}+b_{3} h_{c}^{s s} \vartheta^{c} \widehat{m}_{t}-\vartheta^{c} E_{t} \sum_{j=0}^{\infty}\left(r_{t+j}-r^{s s}\right)
$$

Current consumption depends positively on the state of preferences $\zeta_{t}$, and on current real money balances $\widehat{m}_{t} ;$ and in a negative fashion on the "long-run" real interest rate $E_{t} \sum_{j=0}^{\infty}\left(r_{t+j}-r^{s s}\right)$.
} 
The existence of a (non-separable) transaction costs function in the budget constraint gives rise to the presence of monetary elements in the consumption Euler equation.

\section{The investment function.}

The decision regarding the quantity to invest is governed the next period's capital first order condition $\left(k_{t+1}^{f o c}\right)$. As it can be seen above that equation depends on the Lagrange multiplier $\xi_{t+1}$. Recalling the implicit optimality condition for next period's demand of labor $\left(n_{t+1}^{f o c}\right)$, it is obtained $\xi_{t+1}=\lambda_{t+1} \frac{w_{t+1}}{f_{n_{t}+1}}$. After substituting that result in $\left(k_{t+1}^{f o c}\right)$ the investment decision will be optimal when holding

$$
\lambda_{t}\left(1+C_{x_{t}}\right)=\beta E_{t}\left[\lambda_{t+1}\left(1-\delta+(1-\delta) C_{x_{t+1}}+\frac{w_{t+1}}{f_{n_{t+1}}} f_{k_{t+1}}\right)\right] .
$$

On the left hand side we have, in utility units, the marginal costs coming from the last unit of investment taken. On the right hand side, we have the expected marginal benefits in utility units as well. There are two ways to increase utility by using capital: some adjustment costs saved for the future $(1-\delta) C_{x_{t+1}}$, and the savings in terms of labor costs thanks to the use of physical capital resources $\frac{w_{t+1}}{f_{n_{t+1}}} f_{k_{t+1}}$. It is interesting to emphasize that the latter is measured in terms of a substitution effect of using more capital and saving some labor considering that the final amount produced does not vary since it is demand constrained.

When we incorporate the relation $\beta E_{t} \lambda_{t+1}=\lambda_{t}\left(1+r_{t}\right)^{-1}$ the Lagrange multipliers cancel out resulting in

$$
1+C_{x_{t}}=\frac{1-\delta+(1-\delta) C_{x_{t+1}}+\frac{w_{t+1}}{f_{n_{t+1}}} f_{k_{t+1}}}{1+r_{t}}
$$

Now we will assume the existence of a Cobb-Douglas production function,

$$
f\left(z_{t}, n_{t}, k_{t}\right)=\exp \left(z_{t}\right) n_{t}^{1-\alpha} k_{t}^{\alpha}
$$

and an adjustment cost specification used in Abel (1983), and more recently in Casares and McCallum (2000), 


$$
\begin{gathered}
C\left(x_{t}\right)=\varphi x_{t}^{\nu} \\
\text { with } \quad \varphi>0 \quad \text { and } \quad \nu>1 .
\end{gathered}
$$

The functional form (14) implies increasing marginal adjustment cost. Since the production function $f($.$) is homogeneous of degree 1$, we have a production function net of adjustment $\operatorname{costs} f\left(z_{t}, n_{t}, k_{t}\right)-C\left(x_{t}\right)$ that implies decreasing returns to scale. In other words, the ratio of total adjustment costs to output would increase with the size of the production plant, discouraging the existence of large plants.

Plugging the production function (13) and the adjustment cost function (14) in the investment first order condition (12), log-linearizing, and solving out for $\widehat{x}_{t}$, it yields the following investment equation

$$
\widehat{x}_{t}=(1-\delta) E_{t} \widehat{x}_{t+1}+\vartheta^{x} \psi^{s s} f_{k}^{s s}\left(E_{t} \widehat{\psi}_{t+1}+E_{t} \widehat{f}_{k_{t+1}}\right)-\vartheta^{x}\left(r_{t}-r^{s s}\right),
$$

where $\vartheta^{x}=\frac{1}{C_{x}^{s s}(\nu-1)}$, and $\widehat{\psi}_{t+1}=\widehat{w}_{t+1}-\widehat{f}_{n_{t+1}}$ is the percent deviations from steady state of the real marginal cost (in terms of labor) faced by the households. Regarding the latter, it enters the investment function with a positive sign. When the real marginal cost is expected to rise $\left(E_{t} \widehat{\psi}_{t+1}>0\right)$, labor becomes more costly and households substitute units of labor for units of capital; investment rises. Likewise, if the capital marginal productivity is expected to be larger in the next period $\left(E_{t} \widehat{f}_{k_{t+1}}>0\right)$ households will decide to invest more in the current period. The third variable affecting investment decisions is the real interest rate which represents the opportunity cost missed. Government bonds yield $r_{t}$ for the next period and households could be obtaining that return if they switched their physical assets (capital goods) to financial assets (bonds). Hence, the real interest rate enters the investment equation with a negative sign. The value of $\vartheta^{x}$ is the semi-elasticity of current investment with respect to the real interest rate (comparable to $\vartheta^{c}$ therefore). Interestingly, the larger the marginal adjustment costs of investment $\left(C_{x}^{s s}\right)$ are, the smaller the semi-elasticity $\vartheta^{x}$ is, implying a lower variability of investment over the business cycle.

\section{The money demand function.}

The amount of real money balances optimally held is determined by the $\left(m_{t}^{f o c}\right)$ first 
order condition derived above. Considering that expression together with the intertemporal relation $\beta E_{t} \lambda_{t+1}=\lambda_{t}\left(1+r_{t}\right)^{-1}$, we reach:

$$
E_{t}\left[\left(1+r_{t}\right)\left(1+\pi_{t+1}\right)\right]=\frac{1}{1+h_{m_{t}}},
$$

which, defining the nominal interest through Fisher equation, is equivalent to say:

$$
1+R_{t}=\frac{1}{1+h_{m_{t}}}
$$

Again, the optimality condition collapses to a marginal benefit/marginal cost equality. In this case, the marginal (opportunity) cost is the nominal interest rate missed and the marginal benefit is the reduction in transaction costs due to the use of monetary services. The value of $h_{m_{t}}$ was obtained from the transaction technology function (9) and then plugged in (16) so that the resulting relation was log-linearized to obtain the money demand function

$$
\widehat{m}_{t}=\frac{b_{2}}{1+b_{3}} \widehat{c}_{t}-\frac{1}{R^{s s}\left(1+b_{3}\right)}\left(R_{t}-R^{s s}\right) .
$$

Real money balances depend positively on the amount consumed and negatively on the nominal interest rate. The three equations analyzed so far (consumption, investment, and money demand) describe the demand behavior of the economy. The supply side will be studied now through the calculation of the so-called new Phillips curve.

The inflation equation: the new Phillips curve.

We depart from the selling price first order condition $\left(P_{t}^{f o c}\right)$ calculated above for the case in which the household can set a new price. The resulting equation can be rearranged to be solved out for $P_{t}$ as follows

$$
P_{t}=\frac{\theta}{\theta-1} E_{t}\left[\frac{\sum_{j=0}^{\infty} \eta^{j} Q_{t, t+j} \psi_{t+j}\left(P_{t+j}^{A}\right)^{\theta} y_{t+j}^{A}}{\sum_{j=0}^{\infty} \eta^{j} Q_{t, t+j}\left(P_{t+j}^{A}\right)^{\theta-1} y_{t+j}^{A}}\right],
$$


with $\psi_{t+j}=\frac{w_{t+j}}{f_{n_{t+j}}}$ again as the real marginal cost and $Q_{t, t+j}$ being the stochastic discount factor from period $t$ to period $t+j$. The previous expression can be log-linearized to obtain ${ }^{6}$

$$
\log P_{t}=\beta \eta E_{t} \log P_{t+1}+(1-\eta) \log P_{t}^{A}+(1-\eta) \widehat{\psi}_{t} .
$$

The resulting expression implies that the price set by the household depends positively on the expected future evolution of both the price level and the real marginal costs. The discount rate employed is $(1-\beta \eta)^{-1}$ per period. As for the aggregate price level, we have the Dixit-Stiglitz index:

$$
P_{t}^{A}=\left[\sum_{j=0}^{\infty}(1-\eta) \eta^{j} P_{t-j}^{1-\theta}\right]^{\frac{1}{1-\theta}},
$$

in which $(1-\eta) \eta^{j}$ is the fraction of households that set a new a price $j$ periods ago. This definition of $P_{t}^{A}$ is equivalent to

$$
P_{t}^{A}=\left[(1-\eta) P_{t}^{1-\theta}+\eta\left(P_{t-1}^{A}\right)^{1-\theta}\right]^{\frac{1}{1-\theta}}
$$

that in log-linear percent deviations from steady state can be expressed as follows

$$
\log P_{t}^{A}=(1-\eta) \log P_{t}+\eta \log P_{t-1}^{A} .
$$

Combining equations (19) and (20), and using the definition of inflation $\pi_{t}=\log P_{t}^{A}-\log P_{t-1}^{A}$ results in the following inflation new Phillips curve formulation

$$
\pi_{t}=\beta E_{t} \pi_{t+1}+\frac{(1-\beta \eta)(1-\eta)}{\eta} \widehat{\psi}_{t}
$$

${ }^{6}$ In steady state, it can be found:

$$
\frac{w^{s s}}{f_{n}^{s s}}=\psi^{s s}=\frac{\theta-1}{\theta} \frac{1-\beta \eta(1+\pi)^{\theta-1}}{1-\beta \eta(1+\pi)^{\theta}} .
$$

While loglinearizing, we assumed $\psi^{s s}=\frac{\theta-1}{\theta}$ since the factor that post-multiplies $\frac{\theta-1}{\theta}$ is very close to one after calibration. When either $\pi=0$ (constant prices) or $\eta=0$ (no sticky prices) the assumption is held exactly. 
The supply behavior of the households is purely forward looking. Current inflation depends positively on the present and all discounted future percent deviations of the real marginal cost with respect to its steady state value. The impact of an increase in the real marginal cost is larger when a higher fraction of firms are altering their price within the quarter, say, when $(1-\eta)$ is larger. Similar derivations of the New Phillips inflation curve can be found in Yun (1996), King and Wolman (1996), Goodfriend and King (1997), or Galí and Gertler (1999).

\section{Monetary Policy Rule.}

The monetary authorities conduct monetary policy in the model by applying a monetary policy rule (MPR) looking for stabilizing the economy over the economic cycle. Assuming that the monetary instrument is the nominal interest rate, one example of a MPR is a generalization of Taylor's rule (Taylor (1993)) with the inclusion of interest rate smoothing

$$
R_{t}-R^{s s}=\left(1-\mu_{3}\right)\left[\mu_{1}\left(E_{t-1} \pi_{t}-\pi^{s s}\right)+\mu_{2} E_{t-1} \widetilde{y}_{t}\right]+\mu_{3}\left(R_{t-1}-R^{s s}\right)+\epsilon_{t} .
$$

where $\mu_{1} \geq 1, \mu_{2} \geq 0,0 \leq \mu_{3}<1$, and $\epsilon_{t}$ is a nominal interest rate shock. ${ }^{8}$ Note that both the output gap $\widetilde{y}_{t}$, and the rate of inflation enter the rule as expectations of next period's values so as to reflect that the monetary authorities do not know actual values when they set the nominal interest rate. Market-clearing (capacity) output is the amount produced when there is equilibrium in both the labor and capital markets. Recalling that labor is

\footnotetext{
${ }^{7}$ The proposed MPR can be reached by combining a more standard Taylor rule:
}

$$
R_{t}^{*}-R^{s s}=\mu_{1}\left(E_{t-1} \pi_{t}-\pi^{s s}\right)+\mu_{2} E_{t-1} \widetilde{y}_{t}
$$

with a partial adjustment equation that includes an error term

$$
R_{t}-R^{s s}=\left(1-\mu_{3}\right)\left(R_{t}^{*}-R^{s s}\right)+\mu_{3}\left(R_{t-1}-R^{s s}\right)+\epsilon_{t},
$$

and where $\mu_{3}$ reflects the degree of interest rate smoothing.

${ }^{8}$ The value of the annualized Taylor coefficient of the output gap in (22) is $\mu_{2}$ multiplied by four. The other two coefficients $\left(\mu_{2}\right.$ and $\left.\mu_{3}\right)$ would remain with the same value in quarterly observations as in annual observations. 
inelastically supplied in one unit of time, the Cobb-Douglas technology implies that capacity output is

$$
\widehat{\bar{y}}_{t}=z_{t}+\alpha \widehat{k}_{t},
$$

while current output $\widehat{y}_{t}$ is demand determined as the weighted sum of consumption, investment (including adjustment costs), and the transaction costs. This equation can be obtained by plugging the government budget constraint in the household's budget constraint so as to reach the overall resources constraint. ${ }^{9}$

\section{Nominal and Real Wages}

The real wage $w_{t}$ is defined as the nominal wage $W_{t}$ divided by the aggregate price level

$$
w_{t}=\frac{W_{t}}{P_{t}^{A}}
$$

There are two types of nominal wages signed in the economy. ${ }^{10}$ The first type is a "fixed" contract: nominal wage is growing at the steady-state rate of inflation. Accordingly the nominal wage in period $t$ would be predetermined following the rule $W_{t}=W_{t-i}\left(1+\pi^{s s}\right)^{i}$. In the second type, the nominal wage grows at the expected inflation of the quarter of the contract: $W_{t}=W_{t-1}\left(1+E_{t-1} \pi_{t}\right)$. Note that this type of contract also gives rise to a predetermined nominal wage. The average nominal wage will be a linear combination of both types. In particular, it will be assumed that there is a probability $\kappa$ that the nominal wage

\footnotetext{
${ }^{9}$ Combining (6) with the government budget constraint $g_{t}=m_{t}-\left(1+\pi_{t}\right)^{-1} m_{t-1}+\left(1+r_{t}\right)^{-1} b_{t+1}-b_{t}$, and assuming that the labor demand dominates in the labor market and becomes the effective amount of labor employed, it is obtained the overall resources constraint:$$
y_{t}-C\left(x_{t}\right)=c_{t}+x_{t}+h\left(c_{t}, m_{t}\right),
$$$$
\text { which in log-linear magnitudes becomes the demand-determined output: }
$$$$
\widehat{y}_{t}=\frac{c^{s s}}{y^{s s}} \widehat{c}_{t}+\frac{x^{s s}+C\left(x^{s s}\right)}{y^{s s}} \widehat{x}_{t}+\frac{h^{s s}}{y^{s s}} \widehat{h}_{t}
$$

${ }^{10}$ Optimizing criteria was not employed to derive nominal wages because we consider that typically they are signed so as to maintain the purchasing power of the workers. Thus, neither employers nor employees have market power to decide over nominal wages.
} 
was signed incorporating the inflation revision and a probability $(1-\kappa)$ that the nominal wage was given by the first contract rule. Consequently, the average real wage $w_{t}$ will be:

$$
w_{t}=\kappa \frac{W_{t-1}\left(1+E_{t-1} \pi_{t}\right)}{P_{t}^{A}}+(1-\kappa) \frac{W_{t-1}\left(1+\pi^{s s}\right)}{P_{t}^{A}}
$$

Multiplying and dividing by $P_{t-1}^{A}$ we reach

$$
w_{t}=\kappa w_{t-1} \frac{\left(1+E_{t-1} \pi_{t}\right)}{\left(1+\pi_{t}\right)}+(1-\kappa) w_{t-1} \frac{\left(1+\pi^{s s}\right)}{\left(1+\pi_{t}\right)},
$$

that after log-linearizing results in the linear real wage equation

$$
\widehat{w}_{t}=\widehat{w}_{t-1}-\kappa\left(\pi_{t}-E_{t-1} \pi_{t}\right)-(1-\kappa)\left(\pi_{t}-\pi^{s s}\right) .
$$

The real wage falls when either the rate of inflation is above its steady state value (because of the fixed nominal contracts) or when there is a positive inflation "surprise", i.e., current inflation is greater than expected inflation (because of the revised contracts). If all the contracts are revised in every period according to expected inflation $(\kappa=1)$, there would only be an inflation surprise effect. On the contrary, if all the contracts are signed according to the steady-state inflation rule $(\kappa=0)$, the difference between current and steady-state inflation would be the only determinant in the change of the real wage.

In the end, the dynamic model described here consists of sixteen rational expectations linear equations and sixteen endogenous variables as shown in the Appendix of this paper. A previous step to solving the model is the calibration/estimation of its parameters.

\section{Estimation and Calibration}

This section is devoted to estimate and calibrate the model with euro area data so that the parameters of the structural equations derived in the previous section take certain values. Five macroeconomic series were utilized in the estimation/calibration procedures conducted below: consumption, investment, inflation, short-run nominal interest rate, and the narrow definition for the monetary aggregate, M1. Our source is the area-wide model data base developed by Fagan, Henry, and Mestre (2000). All these variables are given in quarterly 
observations, seasonally adjusted, and were aggregated using fixed weights based on real GDP at PPP rates. Deflated series were calculated in 1990 price level. Consumption definition is real Private Final Consumption Expenditures whereas investment is real Gross Fixed Capital Formation. The inflation rate is the quarter-to-quarter change in the log of the GDP deflator and the nominal interest rate is an average of national three-month interbank (annual) rates divided by four to be expressed in quarterly units. The monetary aggregate M1 comprises currency in circulation and overnight deposits. This narrow definition of the monetary aggregate was selected so as to represent the medium of exchange role of money, with perfect liquidity and zero nominal return. The sample period analyzed is 1970.11998.4 except for estimation/calibration involving M1 where we start by the first available observation in 1980.1 .

In a Sidrauski-type model such as the one at hand, the steady state real interest rate $r^{s s}$ is equal to the rate of intertemporal preference $\rho$. As we considered the length of a period here to be equal to one quarter we set arbitrarily $\rho=r^{s s}=0.005$ in order to imply a $2 \%$ real interest rate per year. The baseline steady-state rate of inflation is $\pi^{s s}=0.005$, i.e. $2 \%$ per year. Hence, the steady-state nominal interest rate is $R^{s s}=r^{s s}+\pi^{s s}=0.01$ per quarter, or $4 \%$ per year.

The money demand and consumption equations were estimated to determine the figures assigned to the parameters $\sigma, b_{2}$, and $b_{3}$. We start with money demand estimation. The coefficients $b_{2}$ and $b_{3}$ from the transaction costs function (9) fully determine the elasticities of consumption and the nominal interest rate in the money demand equation (17). In order to estimate $b_{2}$ and $b_{3}$, then, we ran the following OLS regression by taking the real M1, real consumption, and the short-run nominal interest rate series ${ }^{11}$

$$
\begin{aligned}
\log m_{t}= & -1.46+0.8 \log c_{t}-3.1 R_{t} \\
& (0.6) \quad(0.04) \quad(0.75) \\
R^{2}= & 0.93 \quad D W=0.085
\end{aligned}
$$

The interest rate semi-elasticity obtained implies $\frac{1}{R^{s s}\left(1+b_{3}\right)}=3.1$ and then using $R^{s s}=$ $0.01, b_{3}=31.2$. Similarly, the consumption elasticity implies $\frac{b_{2}}{1+b_{3}}=0.8$, and consequently

\footnotetext{
${ }^{11}$ The existence of heavy serial correlation in the residuals led us not to choose GMM estimators because we could not use lagged real money balances as instrumental variables. In any event, the GMM estimates with lagged consumption and nominal interest rates are quite similar to the OLS estimates reported here.
} 
$b_{2}=25.8$. The numbers in parenthesis under the estimates are their standard deviations.

The Durbin-Watson statistic is close to zero indicating high serial correlation in the residuals. The very likely existence of a unit root in the error term brings about poor properties of the estimates. Thus, it would be desirable to compare our results with other empirical works. Recently, Clausen (1998) finds a stable money demand equation for the euro area when including a partial adjustment hypothesis. Furthermore, it is claimed there that stability is greater with M1 than with M3 data. With respect to the size of the elasticities, it is reported a very similar figure for the consumption elasticity and a bit smaller figure for the nominal interest rate semi-elasticity is reported.

The value assigned to $b_{1}$ in (9) implies a steady-state real money over consumption ratio in the model equal to $1.6 .^{12}$ The constant transaction costs $b_{0}$ was calibrated so as to imply that total transaction costs take $1 \%$ of output in steady state $\left(\frac{h^{s s}}{y^{s s}}=0.01\right)$.

The next step is estimate the structural consumption equation (10). We used GMM estimation to obtain:

$$
\begin{gathered}
\log c_{t}=E_{t} \log c_{t+1}-0.65 r_{t}+0.14\left(\log m_{t}-E_{t} \log m_{t+1}\right) \\
\quad(0.24) \quad(0.05) \\
R^{2}=0.99 \quad D W=1.39
\end{gathered}
$$

where the list of instrument variables contains four lags of $\log c_{t}, \log m_{t}, R_{t}$, and $\pi_{t}$. The real interest rate was obtained from the data as $r_{t}=R_{t}-E_{t} \pi_{t+1}$. Expectational variables such as $E_{t} \log c_{t+1}$ and $E_{t} \pi_{t+1}$ were replaced by actual observations. The signs of the coefficients are correct with high significance. In accordance with these results, we set $\sigma=1.25$ in the utility function to yield an interest rate semielasticity (approximately) equal to $-0.65 .^{13}$ Regarding the real money balance elements, its theoretical value in the consumption function is given by $\frac{b_{3} h_{c}^{s s}(.)}{\sigma+\left(b_{2}-1\right) h_{c}^{s s}(.)}$. Once calibrated the values for the parameters in the transaction costs function and the utility function, we can find the steady state solution of the model and then fully determine $\frac{b_{3} h_{c}^{s}(.)}{\sigma+\left(b_{2}-1\right) h_{c}^{s s}(.)}=0.25$. We will maintain this steady-state figure in

\footnotetext{
${ }^{12}$ On quarterly euro area data, the ratio of M1 real money to consumption at constant prices has a sample mean equal to 1.6 during the period 1970.1-1998.4.

${ }^{13}$ The interest rate semielasticity is equal to $\vartheta^{c}=\frac{1}{\sigma+\left(b_{2}-1\right) h_{c}^{s s}(.)}$ which is quite close to the the inverse of the coefficient of relative risk aversion $\sigma^{-1}$ because the marginal consumption transaction cost $h_{c}^{s s}($.$) is small$ in steady state. If no marginal transaction costs were considered $\left(h_{c}^{s s}=0\right)$ we would have $\vartheta^{c}=\sigma^{-1}$.
} 
the model despite the smaller number estimated from the data. There was no conclusive evidence of serial correlation in the residuals which reported a standard deviation equal to 0.006 .

In the Cobb-Douglas production function (13) we set $\alpha=0.36$ as the capital share coefficient. It yields a steady-state ratio of consumption over investment near 3 , as consistent with euro area observations that report a $c_{t} / x_{t}$ sample mean equal to 2.99 for the period 1970.1-1998.4.

The structural investment equation (15) is calibrated so as to match the degree of variability of investment observed in the data. Hence, we assign a semielasticity of investment with respect to the real interest rate $\vartheta^{x}$ such that the variability of investment relative to the variability of consumption is equal to figures observed in actual data. Series of consumption and investment from 1970.1 to 1998.4 were logged and filtered using the Hodrick-Prescott technique as standard in the literature in order to extract the cyclical (stationary) component of the original series. Then, we calculated the standard deviation of the transformed series and found that the standard deviation of investment is around three times the standard deviation of consumption. Thus, we intended to match this ratio of standard deviations by setting an adequate value for $\vartheta^{x}$. It turned out that the required semi-elasticity should be 5 . In addition, the size of the total adjustment cost is considered to be $4 \%$ of total investment in steady state. Thus, these two features (semi-elasticity to the expected return over the financial asset and size of the adjustment costs relative to output) were utilized to calibrate the adjustment cost function (14). As a result, it was calibrated $\varphi=0.081$ and $\nu=2.62$. The depreciation rate is $2.5 \%$ per quarter $(\delta=0.025)$.

In the New Phillips curve derived above the only parameter to calibrate is the probability for the household to maintain her price fixed $\eta$. It will me assumed here that households change their price once a year on average which is equivalent to say that the probability to maintain their price is $\eta=0.75$ and the probability to set a new price is $1-\eta=0.25$. Consequently, the number of quarters without changing the price is on average $(1-\eta)^{-1}=4$, i.e., one year.

As for the nominal wage contracting, they are signed with probability $\kappa=0.25$ growing at the expected inflation for next period. In other words, one fourth of the contracts are revised every quarter to incorporate expected deviations of inflation over target. The rest of the contracts imply a nominal increase equal to the steady-state rate of inflation. 
With respect to the proposed MPR, it does not seem to be appropriated any calibration for the current euro area when for the sample period observed (1970.1-1998.4) there were different central banks operating, with different targets, instruments, and observed figures of those targets and instruments. As we got closer to the era of the European Monetary Union, monetary policies were more coordinated and nominal interest rates converged following quite similar paths. However, the shortness of the sample period (starting in 1990 or so) does not allow an accurate estimation of the rule. Our task here will be then some experimenting with a Taylor rule. In section 5 we will check how the model responds to varying the Taylor coefficients so that we can extract some recommendations for applying such rule. As the baseline calibration we set $\mu_{1}=1.50, \mu_{2}=0.20$, and $\mu_{3}=0.75$.

Regarding the stochastic processes hitting the system we had a technology shock to the production function $z_{t}$, a consumption preferences shock to the utility function $\zeta_{t}$, and a monetary policy rule shock $\epsilon_{t}$. It is assumed that the technology shock remains mostly in the process following an $\mathrm{AR}(1)$ with a coefficient of autocorrelation equal to 0.95. The other two shocks are considered to be white noise.

Calibration of parameters.

\begin{tabular}{|c|c|c|c|c|c|}
\hline$\rho=0.005$ & $\alpha=0.36$ & $\mu_{1}=1.50$ & $b_{0}=0.0321$ & $\eta=0.75$ & $\pi^{s s}=0.005$ \\
$\beta=0.995$ & $\delta=0.025$ & $\mu_{2}=0.20$ & $b_{1}=526166$ & $\kappa=0.25$ & $r^{s s}=0.005$ \\
$\sigma=1.25$ & $\varphi=0.081$ & $\mu_{3}=0.75$ & $b_{2}=25.8$ & & $R^{s s}=0.01$ \\
& $\nu=2.62$ & & $b_{3}=36.2$ & & \\
\hline
\end{tabular}

\section{Business Cycle Analysis}

The sixteen-equation model was solved as a linear rational expectations system of equations. We ran Paul Klein's algorithm "solvek.m" in MatLab in order to find the minimal state variable solution of the system (see Klein (1997) and McCallum (1999b) for the technical particularities). The solution is expressed as decision rule functions of the endogenous variables responding to the state variables. There are two types of state variables: predetermined and exogenous (shocks).

Impulse response functions were calculated to see how endogenous variables respond to the three shocks hitting the system. Figures 1-3 plot the results. The response functions 
shown in order of appearance from left to right and top to bottom correspond to: current output (y), market-clearing output (ybar), consumption (c), investment (x), marginal product of capital (fk), marginal product of labor (fn), the real wage (w), inflation, the real interest rate $(\mathrm{r})$, and the nominal interest rate $(\mathrm{R})$. The first seven variables represent percent deviations from steady state (for example, output is $\log y_{t}-\log y^{s s}$ ) whereas the rate of inflation, and the nominal and real interest rates are given as simple departures from steady state (for example, inflation is $\pi_{t+j}-\pi^{s s}$ ). The monetary policy rule (22) was applied with the baseline coefficients $\mu_{1}=1.50, \mu_{2}=0.20$, and $\mu_{3}=0.75$ for this business cycle exercise.

A technology shock to the production function gives rise to increases in both marketclearing and current output as we can see in Figure 1. Indeed, changes in production technology are the major factor to explain market-clearing (capacity) output variability (in the other two shocks the response are inappreciable). The responses of consumption, investment and output are very persistent and still noticeable many quarters after the shock, because of the high serial correlation in the shock. Investment moves up by around three times the response of consumption. The rate of inflation and the nominal interest rate are driven down whereas the real interest rate, and the marginal products of capital and labor rise. As labor productivity rises inflation falls because of lower real marginal costs. The real wage shows an increasing pattern as a consequence of the drop in actual inflation from its long-run value. Finally, the nominal interest rate decreases when applying Taylor monetary policy rule to this scenario.

Figure 2 shows the effects of an unexpected increase in the nominal interest rate or, in other words, a monetary policy rule shock. With sticky prices the real interest rate increases in a similar size to the rise of the nominal interest rate. As a result, both consumption and investment fall, the latter being four times the fall of the former. In turn, current output has a significant drop of more than four times the size of the shock. Meanwhile, capacity output slightly falls due to the reduction of the stock of capital via less investment. In addition, inflation moves down right after the shock because the real marginal cost falls due to greater productivity of labor. This increase in the marginal product of labor is caused by less labor hired in the markets where actual output is falling substantially. As for the real wage, it shows some positive response as inflation falls. All the peaks are observed immediately after the shock and little persistence is shown in responses. ${ }^{14}$

\footnotetext{
${ }^{14}$ Indeed, more realistic responses should include some lag in the effects in inflation and in actual output.
} 
In Figure 3 the effects of a positive shock to consumption preferences are described. When consumption is more satisfying, this variable goes up and so current output does. Neither there is significant change in investment nor in capacity output. Labor productivity moves down as more labor force is hired to satisfy demand pressure. On the contrary, the marginal product of capital increases because of the absence of new capital entering the production function as investment does not change. ${ }^{15}$ Inflation slightly increases as marginal cost rises with a lower marginal product of labor. The presence of a positive output gap does not lead to changes in the nominal interest rate because it was not foreseen by the central bank. No persistence is shown in any response due to the lack of serial correlation in the shock.

In summary, variability of current output has its origin in the three shocks, variability of market-clearing (capacity) output almost exclusively in the technology shock, and variability of the inflation and the nominal interest rate stem mostly from the technology shock and monetary policy rule shocks.

\section{Monetary Policy Analysis}

As shown in the recent literature, there are two major ways to bring about a MPR. One way is to proceed by presenting a central bank's loss function whose arguments are the monetary policy targets. The loss function is then minimized subject to aggregate demand and aggregate supply equations that constitute the model of the economy (for examples see Svensson (1999), Clarida, Galí, and Gertler (1999), Woodford (1999)). An implicit reaction function, a MPR, might be written as the optimal response of the monetary policy instrument (typically the nominal interest rate) to current or/and expected values of state variables.

Other authors prefer to propose simple rules that are robust to model settings (e.g., Taylor (1993, 1999), and McCallum (1988, 1999a)). They argue that optimal control can be misleading due to its strict dependence on the definition and calibration of the model.

\footnotetext{
This delay is not achieved with the model at hand. However, the inclusion of a backward-looking element in price-setting decision could result in later peaks in inflation responses (see Galí and Gertler (1999) for one example). Likewise, some habit formation term in the utility function (see Fuhrer (1998)), or a partial adjustment equation between "actual" and "optimal" consumption (or output) would lead to later peaks in output responses.

${ }^{15}$ Note that although the actual marginal product of capital increases, the expected next period's marginal product of capital remains the same and therefore investment does not change.
} 
In addition, the instrument reaction function implicitly derived from optimal control rules becomes convenient for policy making only within small-size models. In large models the number of explanatory variables is very high making the applicability of the MPR costly and subject to many possible computational mistakes.

The type of medium-size model at hand led us to use a simple rule approach because the resulting MPR coming from the optimal control analysis would be quite complex, i.e., with a lot of explanatory variables. Nevertheless, we loose the efficiency property found in optimal control models. As we focus the analysis on the design of easy-to-apply rules the issue of efficiency is not our main concern here.

In Section 2, we already presented the central bank behavior through a simple interest rate rule, a generalization of a Taylor-type rule that incorporates nominal interest rate smoothing:

$$
R_{t}-R^{s s}=\left(1-\mu_{3}\right)\left[\mu_{1}\left(E_{t-1} \pi_{t}-\pi^{s s}\right)+\mu_{2} E_{t-1} \widetilde{y}_{t}\right]+\mu_{3}\left(R_{t-1}-R^{s s}\right)+\epsilon_{t} .
$$

At the beginning of period $t$, the central bank announces the interest rate that will be in effect during that period. For stabilizing purposes, both expected inflation deviations and the output gap should have a positive impact on the interest rate and therefore present positive coefficients in (22). Moreover, the coefficient attached to $\left(E_{t-1} \pi_{t}-\pi^{s s}\right)$ should be greater than one so as to rise the real interest rate when there is inflationary pressure. Otherwise, there would be demand expansion and greater inflationary pressure due to increasing real marginal costs.

A monetary policy performance exercise for the euro area can be carried out by calculating standard deviations of the target variables of the estimated model under Taylor's rule for various figures assigned to $\mu_{1}, \mu_{2}$, and $\mu_{3}{ }^{16}$ In our analysis, we study how changes in the coefficients of the rule affect variability of the rate of inflation, the output gap, and the nominal interest rate to evaluate the stabilizing properties of the rule and define an appropriate range of coefficients. Thus, it can be seen in Figures 4, 5, and 6 how standard deviations of the rate of inflation, the output gap, and the nominal interest rate are altered

\footnotetext{
${ }^{16}$ As needed, we set standard deviations for the shocks of the model: the technology innovation entering the production function has a standard deviation equal to 0.007 (as standard in the Real Business Cycle literature), the consumption preferences shock has a standard deviation 0.006 (as estimated via the consumption structural equation in Section 3), and the MPR shock is (arbitrarily) set with a standard deviation equal to 0.001 in order to imply a high degree of nominal interes rate control with little unsystematic variability.
} 
when increasing $\mu_{1}$ from 1.0 to $5.0, \mu_{2}$ from 0.0 to 1.0 , and $\mu_{3}$ from 0.0 to 1.0.

After examining the figures, one may reach the following conclusions for the intervals of coefficients at hand:

- An increase in the inflation coefficient $\mu_{1}$ (see Figure 4):

- decreases variability of inflation.

- increases variability of the output gap.

- increases variability of the nominal interest rate.

- An increase in the output gap coefficient $\mu_{2}$ (see Figure 5):

- increases variability of inflation (except when $\mu_{2}$ is close to 0.0).

- decreases variability of the output gap.

- decreases variability of the nominal interest rate.

- An increase in the nominal interest rate smoothing coefficient $\mu_{3}$ (see Figure 6):

- does not significantly change variability of inflation (except when $\mu_{3}$ is close to 1.0).

- does not significantly change variability of the output gap (except when $\mu_{3}$ is close to 1.0$)$.

- decreases variability of the nominal interest rate (except when $\mu_{3}$ is close to 1.0).

Three monetary policy recommendations stem from the results of these simulations:

1) A large responsiveness to inflation deviations, i.e., large $\mu_{1}$, would lead to too high output gap volatility.

2) A medium-size responsiveness to the output gap is desirable. If it were the case that $\mu_{2}$ is close to 0.0 , the three standard deviations could be moved down by rising $\mu_{2}$. By contrast, a large value of $\mu_{2}$-from 0.5 onwards- does not produce a visible reduction in the output gap standard deviation.

3) A moderate degree of interest rate smoothing is beneficial for the economy because it does not substantially affect either the output gap or the inflation variability whereas it reduces the nominal interest rate variability. A low volatility of the nominal interest rate has been both pursued by central bankers in recent years and recommended in the literature. Apart from the arguments related to caution described in Clarida, Galí, and Gertler (1999), a small standard deviation of the nominal interest rate would also be desirable to make less likely to fall on the zero lower bound (see McCallum (2000) on this matter). Thus, we recommend certain degree of interest rate smoothing. On the contrary, an interest rate smoothing with a coefficient on the vicinity of 1.0 would be harmful because the three 
standard deviations show a sharp increasing pattern. Therefore a number around 0.7 or 0.8 would satisfy our goals of nominal interest rate stability.

Summarizing, the baseline triplet of numbers initially proposed $(1.50,0.20,0.75)$ seem to perform quite well in the simulations of the calibrated model. Perhaps, both the inflation and the output gap coefficients, $\mu_{1}$ and $\mu_{2}$, could be raised a little bit so that the inflation and output gap volatility respectively fall. However, when $\mu_{1}$ is greater than 2.0 the standard deviation of the output gap begins to rise rapidly as mentioned above. In addition, when $\mu_{2}$ reaches 0.5 the reduction of the output gap variability vanishes. Accordingly, the triplet of coefficients with reasonably good performance are values of $\mu_{1}$ between 1.5 and 2.0, values of $\mu_{2}$ between 0.2 and 0.5 , and values of interest rate smoothing around $\mu_{3}=0.75$.

Accompanying the birth of the European Monetary Union, there has been much research work recently published on the issue of monetary policy in the euro area. In this regard, it is remarkable the paper by John Taylor (see Taylor (1999)) where he carries out a robustness exercise with Taylor rules in nine different models that collect the variety of models appearing in the literature. He concludes that the originally proposed coefficients of his rule $\left(\mu_{1}=\right.$ $1.5, \mu_{2}=\frac{0.5}{4}, \mu_{3}=0.0$ ) perform sufficiently well in all the models and thus he recommends them as a guideline for interest rate setting by the ECB. Our results can be included in his line of argument. When we plug the triplet of Taylor's originally proposed coefficients in the monetary policy rule (22), the percentage annual standard deviations that we obtain in the simulations are low and similar to one for the rate of inflation (1.04), the output gap (1.09), and the nominal interest rate (1.02).

In an empirical work, Gerlach and Schnabel (2000) show that actual behavior of European central bankers regarding interest setting in the 90's are well captured by a Taylor rule with its initially proposed coefficients. In another empirical work, however, Clarida, Galí, and Gertler (1998) find that monetary policies conducted in Germany, Italy, and the UK during the period 1979-1993 were less compelling than Taylor's numbers, as they found estimates for $\mu_{1}$ close to 1.0. Thus, it seems to be the case that as the new era of the European Monetary Union was approaching monetary policy showed a greater degree of responsiveness, as suggested here and elsewhere, for a Taylor rule in the euro area. 


\section{Conclusions}

A Sidrauski-type structural model with monopolistic competition and sticky prices was presented here as a predictive tool for business cycle and monetary policy analysis. The model consisted of an optimizing IS-LM sector with transactions-facilitating money and endogenous investment, a forward-looking inflation equation reflecting sticky prices (new Phillips curve), a real wage equation obtained from staggered and revised nominal contracts, some definitions, and a Taylor-type MPR with a smoothing component. Special attention was focused on deriving the consumption, investment, money demand, and selling price (inflation) structural equations.

The consumption equation obtained is forward looking and depends negatively on the real interest rate and positively on a real money balances element. The investment equation is also forward looking and contains three explanatory variables: the real interest rate with a negative sign and both the expected marginal product of capital and the expected real marginal cost with a negative sign. Interestingly, the existence of endogenous investment in the model allows us to endogenize both capital movements and, consequently, marketclearing (capacity) output. The money demand equation is only affected positively by current consumption and negatively by the nominal interest rate.

On the supply side, the selling price set by the households is also forward looking and depends on two variables: the aggregate price level and the marginal real cost, both of them entering the price equation with a positive sign.

The model was estimated and calibrated for the euro area. A business cycle analysis was conducted by means of impulse response functions that show how the variables of the model react when there is a technology, consumption preferences, or MPR shock. It turned out that output, consumption, and investment fluctuate significantly with changes in technology, consumer's preferences, and monetary policy. As for the inflation and the nominal interest rates, they both move considerably when technology or monetary policy are shocked.

The design of a Taylor monetary policy rule with nominal interest smoothing for the euro area calibrated model was studied in the last part of the paper. We first saw how changing the coefficients may affect the standard deviations of the variables of the model such as the rate of inflation, the output gap or the nominal interest rate. By looking at the performance of the rule when moving the coefficients and assuming that the monetary authorities intend to reduce volatility in the three variables mentioned the results obtained 
take us to the following conclusions: the coefficient of responsiveness to inflation deviations would have to be in the range between 1.5 and 2.0, the output gap coefficient between 0.2 and 0.5 , and the coefficient of nominal interest rate smoothing close to 0.75 . These numbers are a little bit larger than the ones reported in empirical works (Gerlach and Schnabel (2000), and Clarida, Galí, and Gertler (1998)). However, the gap between proposed and actual numbers seems to be smaller as we take a more recent sample period reflecting in some way that the European Central Bank is conducting monetary policy with some more responsiveness than the previous separated national banks.

APPENDIX. An structural model for business cycle and monetary policy analysis.

- Five-equation IS-LM sector (demand behavior):

$$
\begin{aligned}
\widehat{c}_{t} & =E_{t} \widehat{c}_{t+1}-\vartheta^{c}\left(r_{t}-r^{s s}\right)+b_{3} h_{c}^{s s} \vartheta^{c}\left(\widehat{m}_{t}-E_{t} \widehat{m}_{t+1}\right)+\vartheta^{c} \zeta_{t}, \\
\widehat{x}_{t} & =(1-\delta) E_{t} \widehat{x}_{t+1}+\vartheta^{x} \psi^{s s} f_{k}^{s s}\left(E_{t} \widehat{\psi}_{t+1}+E_{t} \widehat{f}_{k_{t+1}}\right)-\vartheta^{x}\left(r_{t}-r^{s s}\right), \\
\widehat{m}_{t} & =\frac{b_{2}}{1+b_{3}} \widehat{c}_{t}-\frac{1}{R^{s s}\left(1+b_{3}\right)}\left(R_{t}-R^{s s}\right), \\
\widehat{h}_{t} & =b_{2}\left(1-\frac{b_{0}}{h^{s s}} \widehat{c}_{t}-b_{3}\left(1-\frac{b_{0}}{h^{s s}}\right) \widehat{m}_{t},\right. \\
\widehat{y}_{t} & =\frac{c^{s s}}{y^{s s}} \widehat{c}_{t}+\frac{x^{s s}+C\left(x^{s s}\right)}{y^{s s}} \widehat{x}_{t}+\frac{h^{s s}}{y^{s s}} \widehat{h}_{t} .
\end{aligned}
$$

- New Phillips curve (supply behavior):

$$
\pi_{t}=\beta E_{t} \pi_{t+1}+\frac{(1-\beta \eta)(1-\eta)}{\eta} \widehat{\psi}_{t}
$$

- Production function. Current output and market-clearing output:

$$
\begin{aligned}
\widehat{y}_{t} & =z_{t}+\alpha \widehat{k}_{t}+(1-\alpha) \widehat{n}_{t} \\
\widehat{\bar{y}}_{t} & =z_{t}+\alpha \widehat{k}_{t}
\end{aligned}
$$

- Monetary Policy Rule:

$$
R_{t}-R^{s s}=\left(1-\mu_{3}\right)\left[\mu_{1}\left(E_{t-1} \pi_{t}-\pi^{s s}\right)+\mu_{2} E_{t-1} \widetilde{y}_{t}\right]+\mu_{3}\left(R_{t-1}-R^{s s}\right)+\epsilon_{t} .
$$


- Real wages:

$$
\widehat{w}_{t}=\widehat{w}_{t-1}-\kappa\left(\pi_{t}-E_{t-1} \pi_{t}\right)-(1-\kappa)\left(\pi_{t}-\pi^{s s}\right) .
$$

- Definitions:

$$
\begin{aligned}
\widetilde{y}_{t} & =\widehat{y}_{t}-\widehat{\bar{y}}_{t}, \\
r_{t} & =R_{t}-E_{t} \pi_{t+1}, \\
\widehat{\psi}_{t} & =\widehat{w}_{t}-\widehat{f}_{n_{t}}, \\
\widehat{f}_{n_{t}} & =\widehat{y}_{t}-\widehat{n}_{t}, \\
\widehat{f}_{k_{t}} & =\widehat{y}_{t}-\widehat{k}_{t}, \\
\widehat{k}_{t+1} & =\delta \widehat{x}_{t}+(1-\delta) \widehat{k}_{t} .
\end{aligned}
$$

This is a rational expectations linear system consisting of sixteen equations (A1)-(A16) and sixteen endogenous variables $\widehat{y}_{t}, \widehat{\bar{y}}_{t}, \widetilde{y}_{t}, \widehat{c}_{t}, \widehat{x}_{t}, \widehat{m}_{t}, \widehat{h}_{t}, \widehat{k}_{t+1}, \widehat{n}_{t}, \widehat{w}_{t}, \widehat{f}_{n_{t}}, \widehat{\psi}_{t}, \widehat{f}_{k_{t}}, R_{t}, \pi_{t}$, and $r_{t}$.

There also are three predetermined variables: $\widehat{k}_{t}, \widehat{w}_{t-1}$, and $R_{t-1}$, and three exogenous processes (shocks): $\zeta_{t}, z_{t}$, and $\epsilon_{t}$.

\section{REFERENCES}

Abel, Andrew, 1983. "Optimal Investment Under Uncertainty," American Economic Review 73 (March), 228-233.

Calvo, Guillermo A., 1983. "Staggered Pricing in a Utility-Maximizing Framework," Journal of Monetary Economics 12 (Sept.), 383-396.

Casares, Miguel, 2000. "Dynamic Analysis in an Optimizing Monetary Model with Transaction Costs and Endogenous Investment," Doctoral Thesis, 61-103.

— , and Bennett T. McCallum, 2000. "An Optimizing IS-LM Framework with Endogenous Investment," NBER Working Paper Series, 7908. 
Clarida, Richard, Jordi Galí, and Mark Gertler, 1998. "Monetary Policy Rules in Practice. Some International Evidence," European Economic Review 42, 1033-1067.

$\longrightarrow,-$, and $\longrightarrow$ 1999. "The Science of Monetary Policy: A New Keynesian Perspective," Journal of Economic Literature 37, 1661-1707.

Clausen, V., 1998. "Money Demand and Monetary Policy in Europe,"

Weltwirtschaftliches Archiv 1998, 134(4), 712-740.

Dixit, Avinash K., and Joseph E. Stiglitz, 1977. "Monopolistic Competition and Optimum Product Diversity," American Economic Review 67, 297-308.

Fagan, Gabriel, Jerome Henry, and Ricardo Mestre (2000). "An Area-wide Model for the EU11," Econometric Modelling Division, European Central Bank, unpublished.

Fuhrer, Jeffrey C., 1998. "An Optimizing Model for Monetary Policy Analysis: Can Habit Formation Help?," mimeo, Federal Reserve Bank of Boston.

Galí, Jordi, and Mark Gertler, 1999. "Inflation Dynamics: A Structural Econometric Analysis," Journal of Monetary Economics 44, 195-222.

Gerlach, Stefan, and Gert Schnabel, 2000. "The Taylor Rule and Interest Rates in the EMU Area," Economic Letters 67, 165-171.

Goodfriend, Marvin, and Robert G. King, 1997. "The New Neoclassical Synthesis and the Role of Monetary Policy," NBER Macroeconomics Annual, MIT Press, 1997.

Kerr, William, and Robert G. King, 1996. "Limits on Interest Rate Rules in the IS Model," Federal Reserve Bank of Richmond Economic Quarterly 82 (Spring), 47-75.

King, Robert G., and Alexander Wolman, 1996. "Inflation Targeting in a St. Louis Model of the 21st Century," NBER Working Paper Series, 5507.

Klein, Paul, 1997. "Using the Generalized Schur Form to Solve a System of Linear Expectational Difference Equations," Working paper. University of Stockholm.

McCallum, Bennett T., 1988. "Robustness Properties of a Rule for Monetary Policy", Carnegie-Rochester Conference Series on Public Policy, 29, 173-204. 
— 1999a. "Issues in the Design of Monetary Policy Rules," in J.B. Taylor and M. Woodford, eds., Handbook of Macroeconomics, Amsterdam: North-Holland.

_ 1999b. "Roles of the Minimal State Variable Criterion in Rational Expectations Models,". NBER. Working paper 7087.

— 2000. "Theoretical Analysis Regarding a Zero Lower Bound on Nominal Interest Rates," Journal of Money, Credit and Banking, 32(4) pt. 2, 870-904.

— Semiclassical Structural Model," Monetary Policy Rules. John B. Taylor (ed.). University of Chicago Press for NBER, 15-45.

Rotemberg, Julio J., and Michael Woodford, 1997. "An Optimizing-Based Econometric Framework for the Evaluation of Monetary Policy," NBER Macroeconomics Annual 1997, B.M. Bernanke and J.J. Rotemberg, eds. MIT Press, Cambridge, MA.

Svensson. Lars E.O.,1998. "Inflation Targeting as a Monetary Policy Rule," Journal of Monetary Economics 43(3), Special Issue on Monetary Policy Rules, 607-654.

Taylor, John B., 1993. "Discretion Versus Policy Rules in Practice,"

Carnegie-Rochester Conference Series on Public Policy, 39, 195-214.

— 1999. "The Robustness and Efficiency of Monetary Policy Rules as Guidelines for Interest Rate Setting by the European Central Bank," Journal of Monetary Economics 43(3), Special Issue on Monetary Policy Rules, 655-680.

Uhlig, Harald, 1999. "A Toolkit for Analyzing Nonlinear Dynamic Stochastic Models Easily," Computational Methods for the Study of Dynamic Economics, Ramón Marimón and Andrew Scott, (eds.), Oxford University Press.

Woodford, Michael, 1999. "Optimal Monetary Policy Inertia," NBER, Working Paper 7261.

Yun, Tack, 1996. "Nominal Price Rigidity, Money Supply Endogeneity, and Business Cycles," Journal of Monetary Economics 37, 345-370. 


\section{Figure I}

Impulse response functions to one unit technology shock to the production function
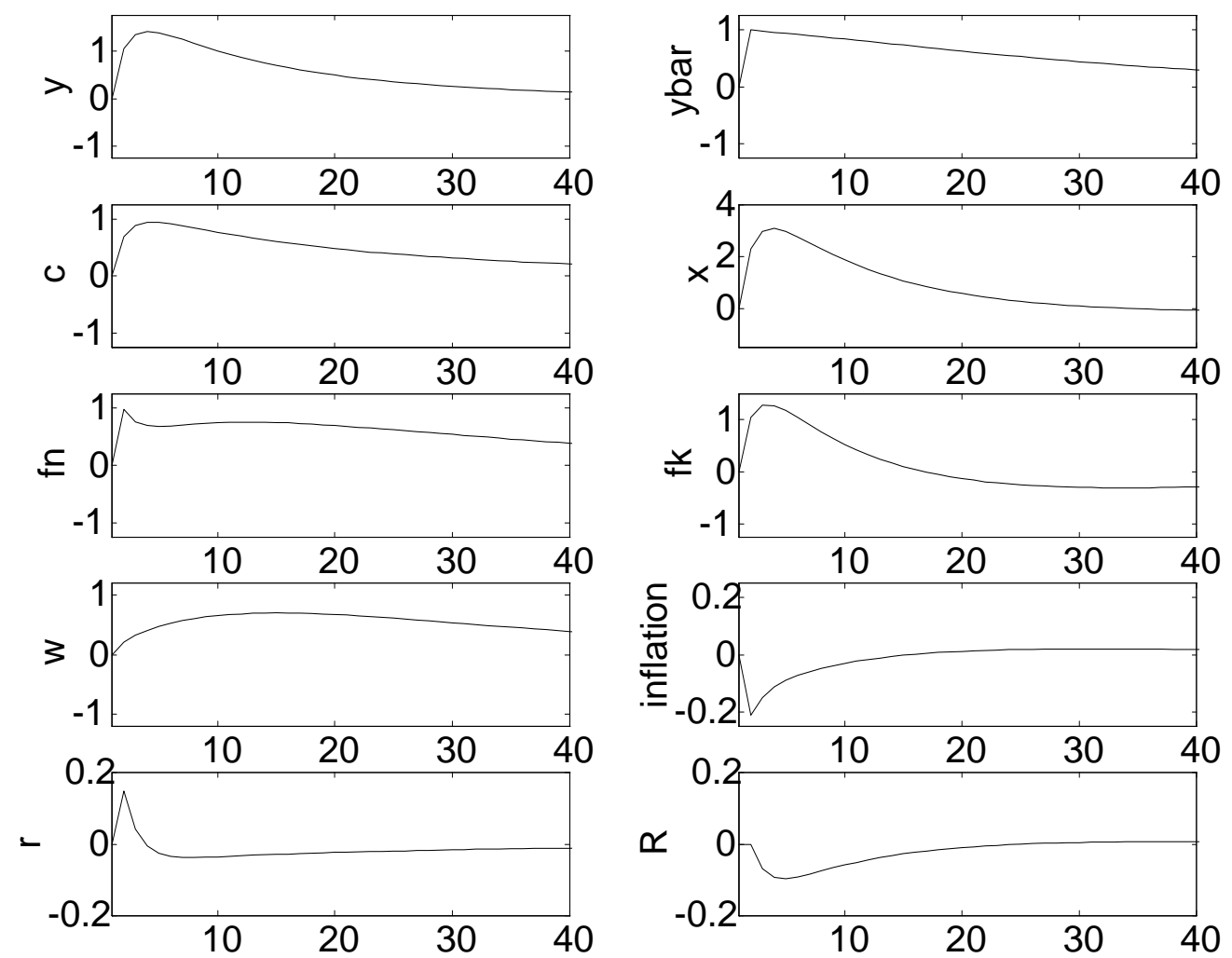


\section{Figure 2}

Impulse response functions to one unit Taylor-type monetary policy rule shock
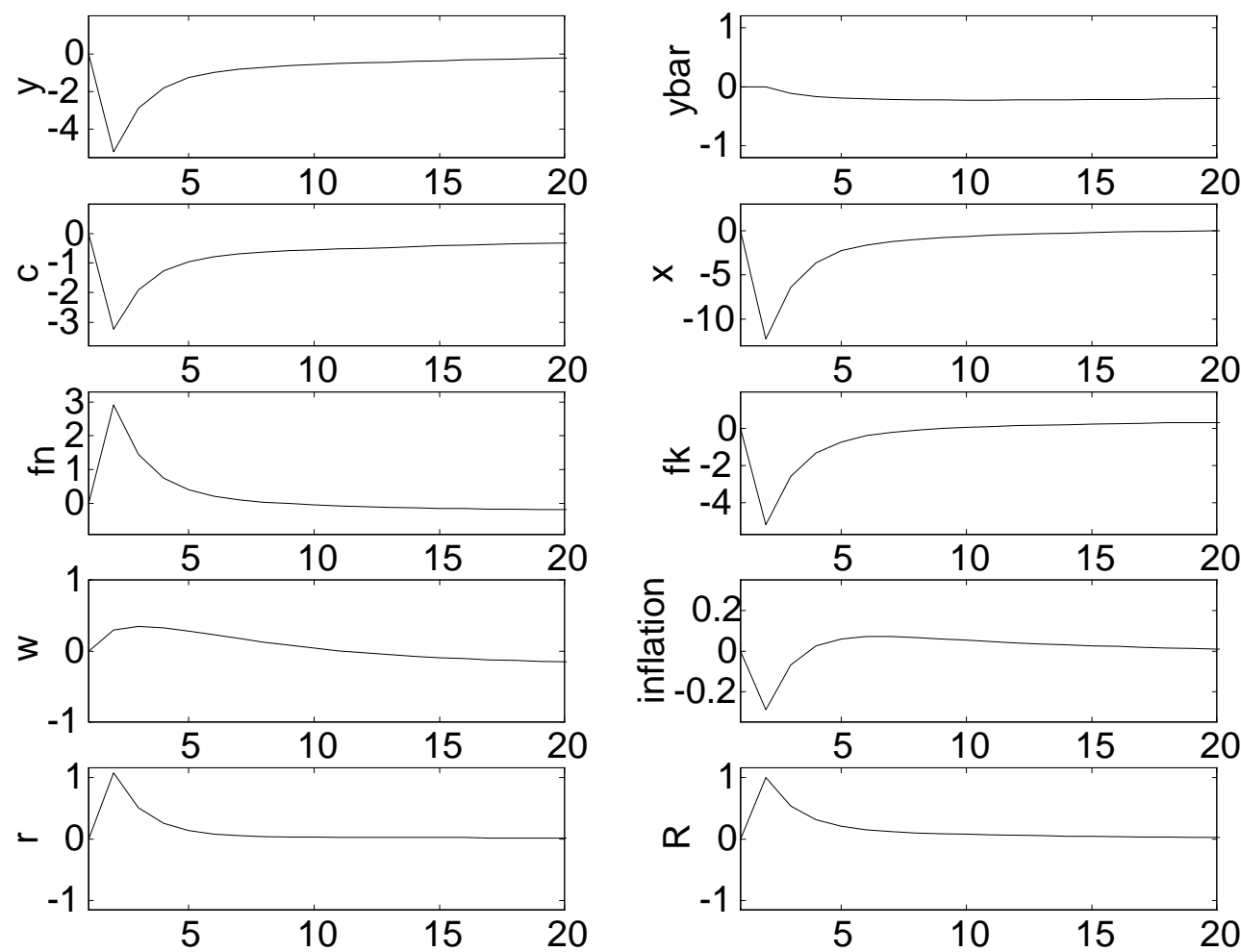


\section{Figure 3}

Impulse response functions to one unit consumption preferences shock in the utility function
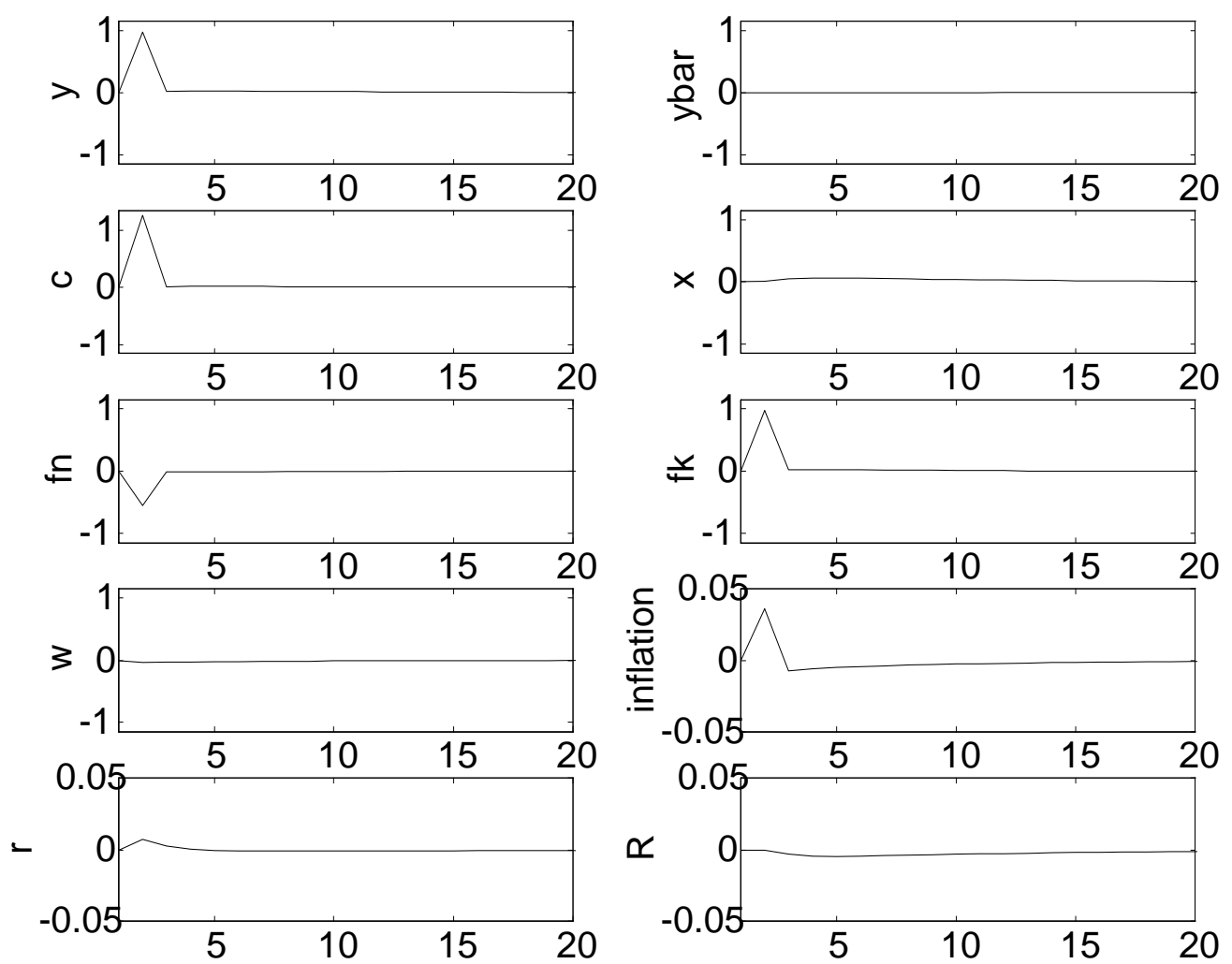


\section{Figure 4}

Taylor rule performance varying $\mu_{1}$ from 1.0 to 5.0. $\mu_{2}$ and $\mu_{3}$ are fixed at their baseline figures

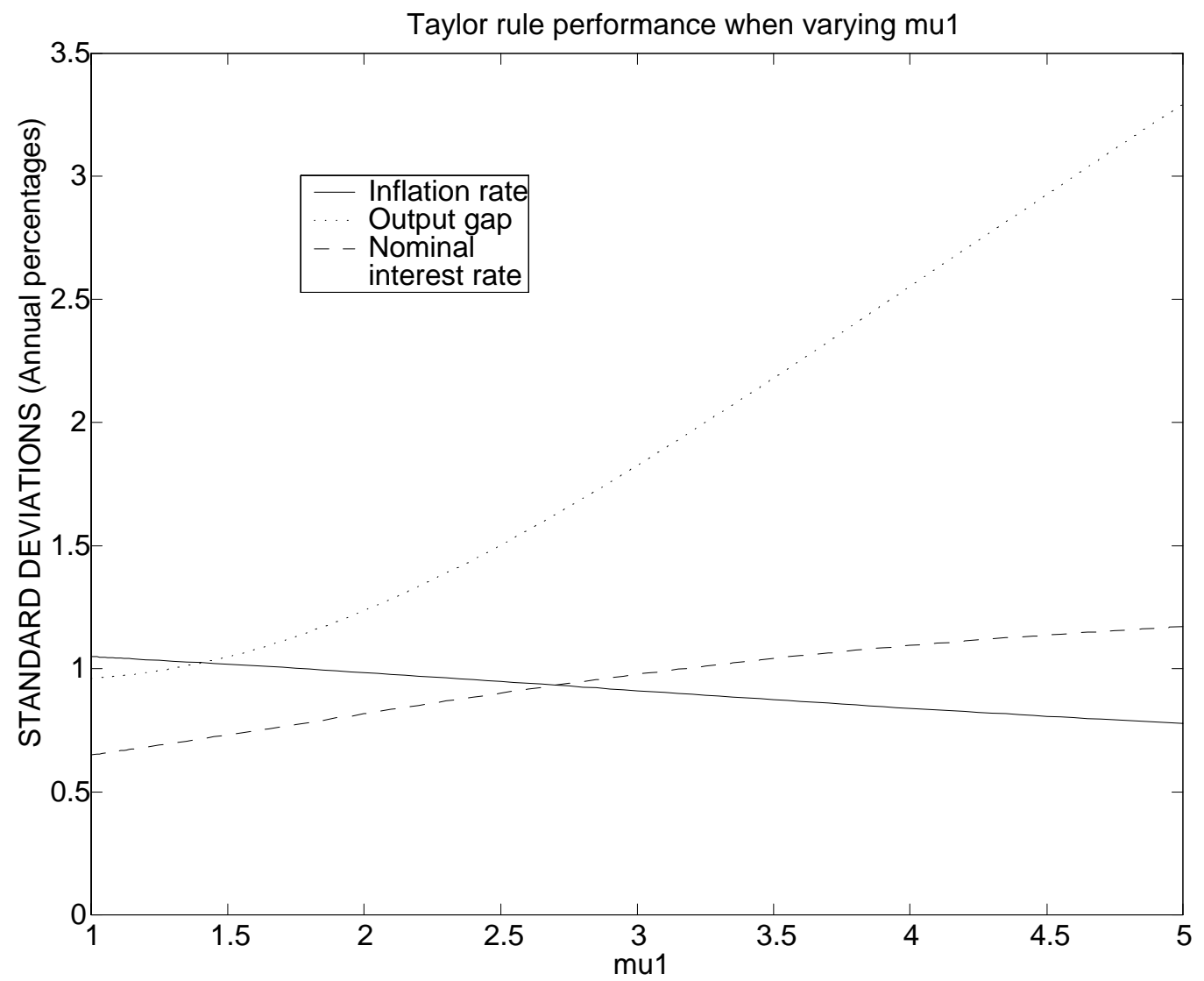




\section{Figure 5}

Taylor rule performance varying $\mu_{2}$ from 0.0 to $1.0 . \mu_{1}$ and $\mu_{3}$ are fixed at their baseline figures.

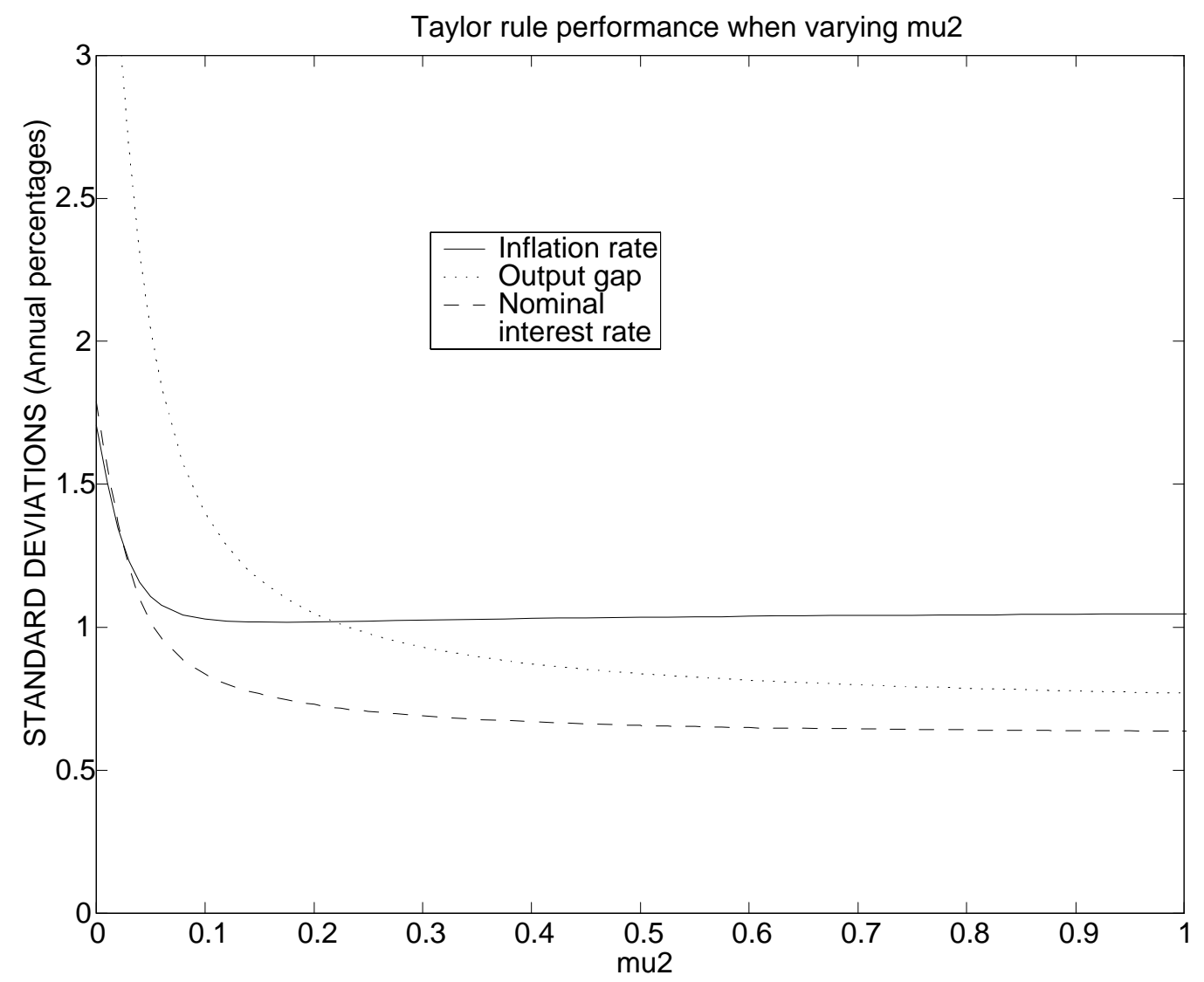




\section{Figure 6}

Taylor rule performance varying $\mu_{3}$ from 0.0 to $0.995 . \mu_{1}$ and $\mu_{2}$ are fixed at their baseline figures.

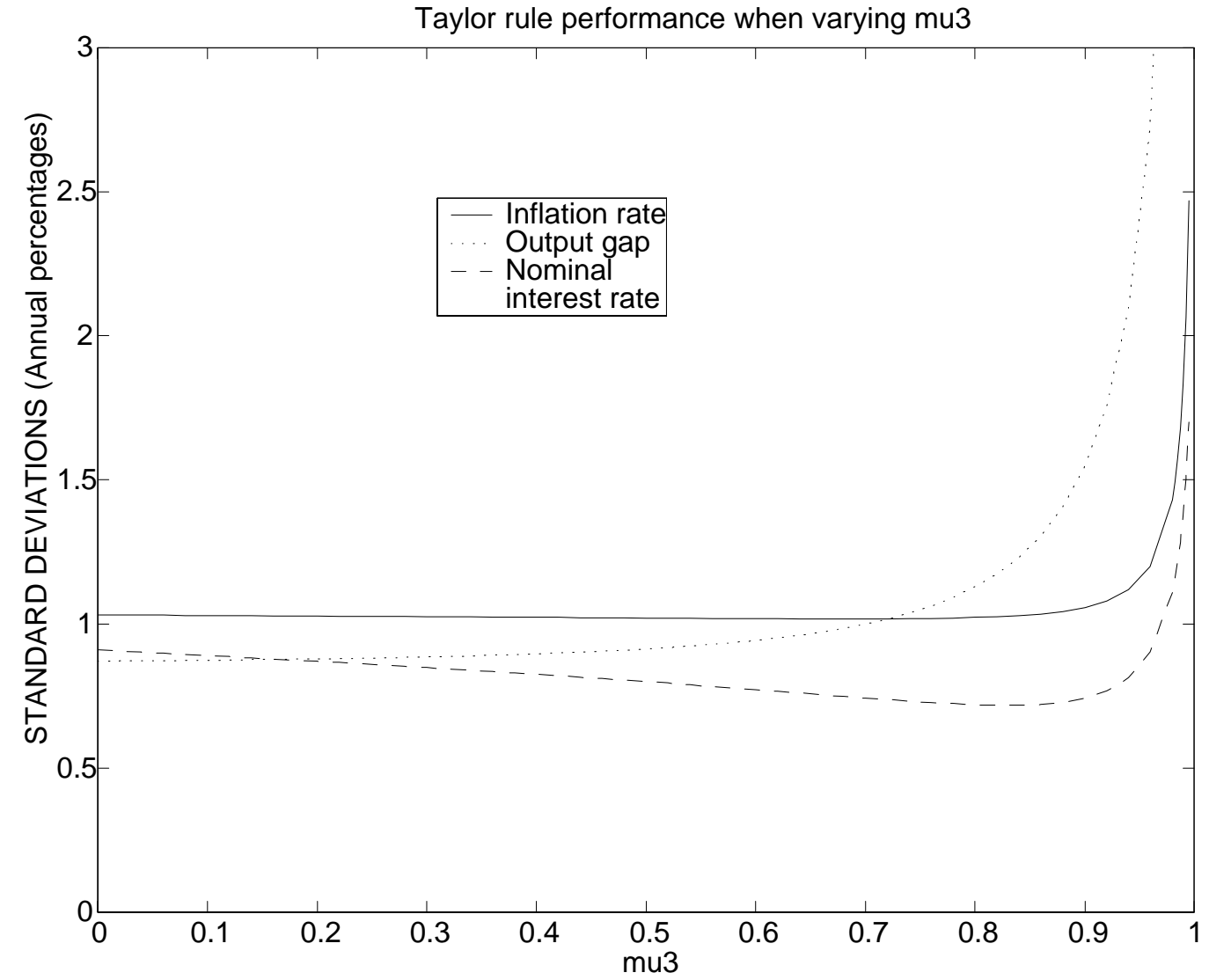




\section{European Central Bank Working Paper Series}

I "A global hazard index for the world foreign exchange markets" by V. Brousseau and F. Scacciavillani, May 1999.

2 "What does the single monetary policy do? A SVAR benchmark for the European Central Bank" by C. Monticelli and O.Tristani, May 1999.

3 "Fiscal policy effectiveness and neutrality results in a non-Ricardian world" by C. Detken, May 1999.

4 "From the ERM to the euro: new evidence on economic and policy convergence among EU countries" by I. Angeloni and L. Dedola, May 1999.

5 "Core inflation: a review of some conceptual issues" by M.Wynne, May 1999.

6 "The demand for M3 in the euro area" by G. Coenen and J.-L.Vega, September 1999.

7 "A cross-country comparison of market structures in European banking" by O. de Bandt and E. P. Davis, September 1999.

8 “Inflation zone targeting” by A. Orphanides and V.Wieland, October 1999.

9 "Asymptotic confidence bands for the estimated autocovariance and autocorrelation functions of vector autoregressive models" by G. Coenen, January 2000.

10 "On the effectiveness of sterilized foreign exchange intervention" by R. Fatum, February 2000.

II "Is the yield curve a useful information variable for the Eurosystem?" by J. M. Berk and P. van Bergeijk, February 2000.

12 "Indicator variables for optimal policy" by L. E. O. Svensson and M. Woodford, February 2000.

13 “Monetary policy with uncertain parameters” by U. Söderström, February 2000.

I4 "Assessing nominal income rules for monetary policy with model and data uncertainty" by G. D. Rudebusch, February 2000.

15 “The quest for prosperity without inflation” by A. Orphanides, March 2000.

I6 "Estimating the implied distribution of the future short term interest rate using the Longstaff-Schwartz model” by P. Hördahl, March 2000.

17 "Alternative measures of the NAIRU in the euro area: estimates and assessment" by S. F. and R. Mestre, March 2000.

I8 "House prices and the macroeconomy in Europe: Results from a structural VAR analysis" by M. lacoviello, April 2000. 
19 "The euro and international capital markets" by C. Detken and P. Hartmann, April 2000.

20 "Convergence of fiscal policies in the euro area" by O. De Bandt and F. P. Mongelli, May 2000.

21 "Firm size and monetary policy transmission: evidence from German business survey data" by M. Ehrmann, May 2000.

22 "Regulating access to international large value payment systems" by C. Holthausen and T. Rønde, June 2000.

23 “Escaping Nash inflation” by In-Koo Cho and T. J. Sargent, June 2000.

24 "What horizon for price stability" by F. Smets, July 2000.

25 "Caution and conservatism in the making of monetary policy" by P. Schellekens, July 2000.

26 "Which kind of transparency? On the need for clarity in monetary policy-making" by B.Winkler, August 2000.

27 "This is what the US leading indicators lead" by M. Camacho and G. Perez-Quiros, August 2000.

28 "Learning, uncertainty and central bank activism in an economy with strategic interactions" by M. Ellison and N.Valla, August 2000.

29 "The sources of unemployment fluctuations: an empirical application to the Italian case" by S. Fabiani, A. Locarno, G. Oneto and P. Sestito, September 2000.

30 "A small estimated euro area model with rational expectations and nominal rigidities" by G. Coenen and V. Wieland, September 2000.

31 "The disappearing tax base: Is foreign direct investment eroding corporate income taxes?" by R. Gropp and K. Kostial, September 2000.

32 "Can indeterminacy explain the short-run non-neutrality of money?" by F. De Fiore, September 2000.

33 "The information content of M3 for future inflation" by C. Trecroci and J. L. Vega, October 2000.

34 "Capital market development, corporate governance and the credibility of exchange rate pegs" by O. Castrén and T.Takalo, October 2000.

35 "Systemic risk:A survey" by O. De Bandt and P. Hartmann, November 2000.

36 "Measuring core inflation in the euro area" by C. Morana, November 2000.

37 "Business fixed investment: Evidence of a financial accelerator in Europe" by P.Vermeulen, November 2000. 
38 "The optimal inflation tax when taxes are costly to collect" by F. De Fiore, November 2000.

39 "A money demand system for euro area M3" by C. Brand and N. Cassola, November 2000.

40 "Financial structure and the interest rate channel of ECB monetary policy" by B. Mojon, November 2000.

4I "Why adopt transparency? The publication of central bank forecasts" by P. M. Geraats, January 2001.

42 "An area-wide model (AWM) for the euro area” by G. Fagan, J. Henry and R. Mestre, January 2001 .

43 "Sources of economic renewal: from the traditional firm to the knowledge firm" by D. R. Palenzuela, February 200 I.

44 "The supply and demand for eurosystem deposits - The first 18 months" by U. Bindseil and F. Seitz, February 200I.

45 "Testing the Rank of the Hankel matrix: a statistical approach" by G. Camba-Mendez and G. Kapetanios, February 200 I.

46 "A two-factor model of the German term structure of interest rates" by N. Cassola and J. B. Luís, February 200I.

47 "Deposit insurance and moral hazard: does the counterfactual matter?" by R. Gropp and J.Vesala, February 2001.

48 "Financial market integration in Europe: on the effects of EMU on stock markets" by M. Fratzscher, March 2001.

49 "Business cycle and monetary policy analysis in a structural sticky-price model of the euro area” by M. Casares, March $200 \mathrm{I}$. 